\title{
Useful information, but still more open questions than answers
}

\author{
Thierry Carrel, MD
}

\author{
From the Department for Cardiovascular Surgery, University Hospital and University of Bern, Bern, Switzerland. \\ Disclosures: Author has nothing to disclose with regard to commercial support. \\ Received for publication Nov 1, 2016; accepted for publication Nov 2, 2016; available ahead of print Dec 10, \\ 2016. \\ Address for reprints: Thierry Carrel, MD, Department for Cardiovascular Surgery, University Hospital, CH-3010 \\ Bern, Switzerland (E-mail: thierry.carrel@insel.ch). \\ J Thorac Cardiovasc Surg 2017;153:519-20 \\ 0022-5223/\$36.00 \\ Copyright (C 2016 by The American Association for Thoracic Surgery \\ http://dx.doi.org/10.1016/j.jtcvs.2016.11.006
}

In a period of increasing financial constraints and economic issues in health care systems, any outcome analysis that may help to optimize early postoperative recovery and thereby shorten overall hospital stay is welcome. In that sense, we must be grateful to Preventza and colleagues ${ }^{1}$ for their analysis in this issue of the Journal of a consecutive cohort of patients who underwent repair or replacement of the aortic root combined with more or less extensive surgery at the level of the aortic arch.

In fact, even in a large institution known for its expertise in aortic surgery, this type of procedure is not frequently performed. In fact, in most cases the pathology is limited to the aortic root, and the aorta can be easily clamped. In another set of cases, the pathology affects mainly the ascending aorta and may extent into the aortic arch, but the aortic root is normal and there is dysfunction of the aortic valve. The article of Preventza and colleagues ${ }^{1}$ summarizes the Houston group's experience with a third group of patients, those in whom aortic root repair or replacement had to be performed concomitantly with a procedure at the level of the aortic arch.

The principal results in the whole cohort of patients are obvious. Increasing age, reoperative surgery, and the amount of intraoperative blood transfusion were found to be significant predictors of the length of hospital stay. ${ }^{2}$ Ventilator support for more than 48 hours was also found to be a predictor of prolonged hospital stay, an association that has been found for several other cardiosurgical procedures.

The cohort was inhomogeneous. It included patients undergoing elective and emergency procedures, patients who required partial or total aortic arch replacement managed with moderate or deep hypothermia (with the potential for significant outcome differences ${ }^{3}$ ), and finally patients treated either by root repair (David procedure) or root replacement (Bentall operation). Subgroup analyses were therefore necessary.

Interestingly but not surprisingly, Preventza and colleagues $^{1}$ found that valve-sparing aortic root repair was followed by a shorter postoperative stay. This conclusion

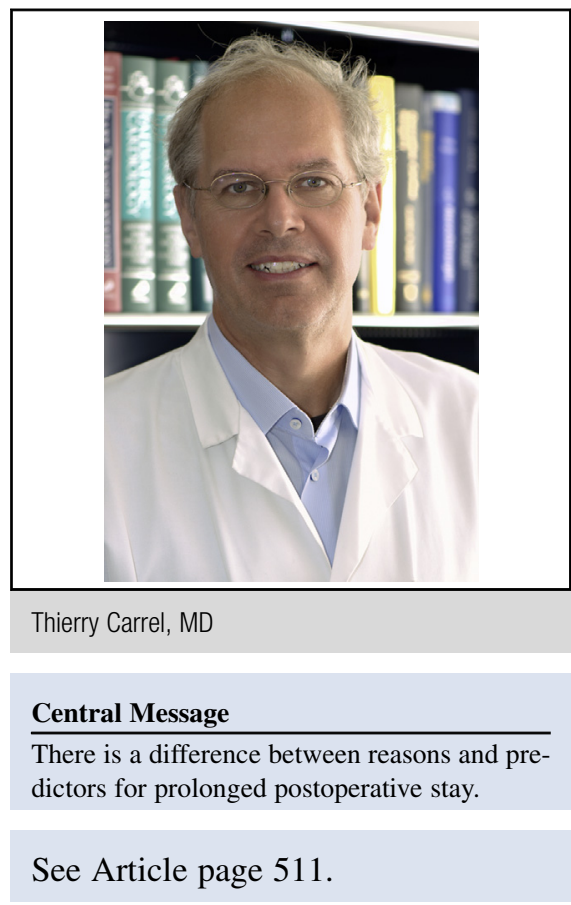

is obvious as well and is most probably explained by a selection bias, because younger patients with almost normal aortic valves were considered appropriate candidates for a David procedure. Because of this association, I found the conclusion that a David procedure per se is a predictive factor for a shorter hospital stay a questionable one.

In my experience during the last 20 years, younger patients who underwent a Bentall procedure (because of a dysfunctional aortic valve) did not demonstrate any differences in the postoperative recovery and length of hospital stay from those who underwent a David procedure. It would be difficult to find reasons why patients with a prolonged perfusion and crossclamp time-which is the case in most valve-sparing root repairs compared with a straightforward Bentall procedure-should recover more quickly and leave the hospital earlier.

As a central message, Preventza and colleagues ${ }^{1}$ defined the David procedure, a more restrictive blood conservation, and a shorter ventilation support as strategies that favorably influence early recovery and decrease the length of hospital stay. This is confirmed in the univariate and multivariate analysis that was performed on the collective of approximately 250 patients. Although these conclusions may be of interest for other institutions dealing with similar 
patients, a substantial number of pertinent questions remain open and may be addressed in future works of this leading group:

- What is the institutional transfusion strategy, and in particular what is the threshold for intraoperative but also postoperative transfusion?

- Did a correlation exist between preoperative anemia and the need for intraoperative transfusion?

- Is there a role for preoperative erythropoietin in patients who are scheduled for elective surgery?

- Can a potential benefit of autologous blood donation be expected in patients who are scheduled for an elective procedure?

- What were the reasons for intraoperative transfusion of packed red blood cells? Was such transfusion necessary during the perfusion because of hemodilution, or did it occur at the end of the procedure because of difficult hemostasis?

- Do Preventza and colleagues ${ }^{1}$ recommend a particular strategy to prepare patients with chronic lung disease to avoid a prolonged intubation and a difficult weaning from the respirator? Is there a role for preoperative topical or systemic steroids, intensive inhalational treatment, and respiratory physiotherapy?

- How should patients with severe smoking habits be handled in case of elective surgery? Should the regimen be abstinence only, or should abstinence be combined with intensive respiratory physiotherapy, nicotine replacement, or medical treatment to ameliorate the effect of nicotine deprivation?

- The term "more complicated distal anastomoses" could be described more precisely, because anastomoses may be complicated by different conditions, such as (1) bad aortic tissue (dissection or atherosclerosis, (2) anatomic difficulty because of deep chest configuration, and (3) the site of the anastomosis: mid arch or distal to the left subclavian artery.

- The institutional strategy to opt for a David procedure could be given more precisely. Preventza and colleagues ${ }^{1}$ described the intraoperative inspection of the aortic leaflets as a main criterion, but what is the value of preoperative or intraoperative transesophageal echocardiography? To spare time for this complex procedure, are there some key findings that may help in making quick decision regarding the type of operation, such as the size of the aortic annulus and the maximum diameter of the sinuses of Valsalva?

- Why should patients undergoing a hemiarch procedure receive significantly less blood transfusion than those undergoing total arch replacement? To play the devil's advocate, in a difficult but typical situation, elective total arch replacement performed in a patient with a good quality of the aorta may be followed by better hemostasis than that encountered in a patient who undergoes supracoronary aortic replacement and emergency hemiarch because of dissection.

- Preventza and colleagues ${ }^{1}$ stated, "The length of stay has been used as a proxy for resource utilization and as an indicator of hospital performance." This might be true, but to be honest they could also mention that sometimes a patient's comorbidities and even preferences may have some significant influence on the discharge process.

One important lesson I took as I read this article was that one should never read the abstract only. The most important points (limitations, potential bias, interpretation of the results and explanations regarding the type of analyses and statistics) are well explained in the discussion, at the end of the article!

\section{References}

1. Preventza O, Coselli JS, Garcia A, Akvan S, Kashyap S, Simpson KH, et al. Aortic root surgery with circulatory arrest: predictors of prolonged postoperative hospital stay. J Thorac Cardiovasc Surg. 2017;153:511-8.

2. Schechter MA, Shah AA, Englum BR, Williams JB, Ganapathi AM, Davies JD, et al. Prolonged postoperative respiratory support after proximal thoracic aortic surgery: is deep hypothermic circulatory arrest a risk factor? J Crit Care. 2016; 31:125-9.

3. Tsai JY, Pan W, Lemaire SA, Pisklak P, Lee VV, Bracey AW, et al. Moderate hypothermia during aortic arch surgery is associated with reduced risk of early mortality. J Thorac Cardiovasc Surg. 2013;146:662-7. 